\title{
Severity of COVID-19 and Treatment Strategy for Patient With Diabetes
}

\author{
Shi $\operatorname{Jin}^{1}$ and Weina $\mathrm{Hu}^{2 *}$ \\ 1 Department of Endocrinology, The Fourth Affiliated Hospital of China Medical University, Shenyang, China, 2 Department of \\ Cardiology, The Fourth Affiliated Hospital of China Medical University, Shenyang, China
}

Coronavirus disease 2019 (COVID-19), which was named by the World Health Organization (WHO) in February 2020, has quickly spread to more than 200 countries around the world and was declared as a global pandemic in March 2020. The severity of the disease makes it more prone to severe symptoms and higher mortality rates in patients, especially those who are with comorbidities, including high blood pressure, cardiovascular disease, obesity, and diabetes, increases the concern over the consequences of this pandemic. However, initial reports do not clearly describe whether diabetes itself or associated comorbidities or treatment strategies contribute to the severe prognosis of COVID-19 infections. Various clinical trials are being conducted on glucose-lowering agents but to date, there is no standard treatment protocol approved for

OPEN ACCESS

Edited by: Jeff M P Holly, University of Bristol, United Kingdom

Reviewed by: Aaron Hanukoglu, Tel Aviv University, Israel Javier Ena, Hospital Marina Baixa, Spain

*Correspondence: Weina Hu cmu4h_huweina@163.com

Specialty section: This article was submitted to Clinical Diabetes, a section of the journal Frontiers in Endocrinology

Received: 04 September 2020 Accepted: 13 April 2021 Published: 30 April 2021

Citation: Jin S and Hu W (2021) Severity of COVID-19 and Treatment Strategy for Patient With Diabetes.

Front. Endocrinol. 12:602735. doi: 10.3389/fendo.2021.602735
COVID-19 cases with pre-existing diabetes. This review is aimed to decipher the potential risk factors of COVID-19 involved from existing evidence. Identification of a novel therapeutic strategy could be beneficial for combating SARS-CoV-2, which might be dreadful to debilitating people who have diabetes.

Keywords: Diabetes mellitus, COVID-19, SARS-CoV-2, cytokine storm, glycemic control

\section{INTRODUCTION}

Severe acute respiratory syndrome coronavirus 2 (SARS-CoV-2), the cause for coronavirus disease 2019 (COVID-19), has infected more than 126 million people in the world and over 2.76 million deaths have been reported worldwide at the time this review was written (1). This virus is a new enveloped beta-coronavirus with a single stand that shares $82 \%$ of genomic similarities with human SARS-CoV, the virus responsible for the SARS pandemic in 2003 (2). SARS-CoV-2 has a higher reproduction rate compared to other beta-coronaviruses such as SARS-CoV and Middle East Respiratory Syndrome (MERS-CoV), indicating a greater risk for global health (3). The COVID-19 outbreak has caused a much higher number of deaths (2.76 million total deaths until March 28th, 2021) than the other coronavirus respiratory syndromes (8096 cases with 774 total deaths for 2003 SARS outbreak while the 2012 MERS outbreak has 2519 confirmed cases with 866 total deaths) $(1,4,5)$. As the number of confirmed cases and death increasing exponentially, using epidemiological data to characterize COVID-19 patients could help to control the spread and also for the development of interventions for the disease. The characteristic of a respiratory virus is multi-organ damage and lungs, heart and kidneys are often the major affected organs.

Studies found that having one or more comorbidities is linked to the increased severity of COVID-19. In a systematic review and meta-analysis with a total number of 46248 confirmed cases, 
data showed that hypertension and diabetes are the most common comorbidities among COVID-19 patients (6). Generally, personal history of diabetes or newly diagnosed diabetes was ascertained in medical records or a self-reported diagnosis with the defined diagnostic criteria according to the WHO diagnostic criteria: fasting plasma glucose $\geq 7.0 \mathrm{mmol} / \mathrm{L}$ ( $\geq 126 \mathrm{mg} / \mathrm{dL}$ ) or 2 -h plasma glucose $\geq 11.1 \mathrm{mmol} / \mathrm{L}$ ( $\geq 200 \mathrm{mg} / \mathrm{dL})$ or HbA1c $\geq 48 \mathrm{mmol} / \mathrm{mol}(6.5 \%)(7,8)$. Studies also found that older age, hypertension, obesity, diabetes, cardiovascular disease, and chronic obstructive pulmonary disease are most commonly observed in patients with severe COVID-19 and those who died $(9,10)$. People with diabetes have a higher risk of viral infection in previous respiratory disease (11). Although diabetes does not seem to increase the risk for COVID-19 in some regions in Europe such as Italy (12), the risk for COVID-19 associated with diabetes is increased in most parts of the world as well as the mortality rates.

However, whether diabetes per se or together with the concomitant comorbidities contribute to the worse prognosis remains to be fully uncovered. Therefore, this review aims to highlight potential risk factors in patients with COVID-19 comorbid with diabetes. We will also discuss the specific therapeutic strategies being used for people who have both COVID-19 and diabetes.

\section{POTENTIAL RISK FACTORS OF COVID-19}

\section{Age and Gender}

COVID-19 morbidity and mortality are higher in older and male individuals. In a systematic literature review and meta-analysis of 13 studies including a total number of 3027 COVID-19 patients and in aged patients over 65 , Zheng et al. reported a greater risk of mortality and more comorbidities such as hypertension, diabetes also greatly affecting the prognosis of the COVID-19 (13). Data from an Israeli study of 5769 recovered patients showed that younger individuals, not only are less likely to have severe COVID-19 requiring ICU and hospitalization but have an average faster recovery rate from SARS-CoV-2 infection (14). In a large Chinese case study of a total of 72314 patients, the fatality rate of the overall case is $2.3 \%$ but it was increased by up to $14.8 \%$ in patients aged 80 and older (15). The prevalence of diabetes is increased with age both in the general population and in patients with COVID-19. Patients with COVID-19 and diabetes have an older average age than those without diabetes. In one retrospective study involving 904 patients with COVID19 (136 with diabetes), patients with diabetes were at least more than 10 years older compared to that of non-diabetic patients (7). Another study including a matched population of patients with and without diabetes found that survivors were much younger than non-survivors and older age (more than 70 years) is an independent predictor of severity of COVID-19 such as inhospital death (16).

A preliminary study showed an overall even distribution of SARS-CoV-2 infections between men and women (51\% versus $47 \%$, respectively) (17). However, the fatality rates are 2 -fold higher in males than females (18). What's more, the sex distribution of recovering cases was $36 \%$ and $65 \%$ for males and females, respectively (19). Another study concluded that male and age serve as risk factors for poorer outcomes in COVID-19. There was a 12 -fold higher risk in patients aged 80 years and older than those 50-59 years old and men have twice the risk as women (20). In a recent risk assessment for the COVID-19 confirmed cases from European Union/European Economic Area (EU/EEA) countries and the United Kingdom (UK), data described that the male-to-female ratio overall was 0.9 , with more males than females admitted to hospital, requiring intensive care or respiratory support and also dying (21).

\section{High Blood Pressure}

High blood pressure (hypertension) is the most common comorbidity in severe COVID-19 patients (22). Studies speculated that SARS-CoV-2 might directly bind to angiotensin-converting enzyme 2 (ACE2) to enter target cells (23). ACE2 is widely expressed in the upper airways, lung, heart, liver, kidney, ileum, testis and brain and it plays an important role in anti-inflammatory responses (24-26). Recent studies have investigated the link between disease severity in COVID-19 patients with hypertension and their medical therapy. In a clinical trial of 3017 hospitalized COVID-19 patients, data showed that $53 \%$ were hypertensive. Besides, the mortality rates among patients on angiotensin-converting enzyme inhibitors (ACEI) and angiotensin receptor blockers (ARBs) treatment were lower compared to other anti-hypertensive drugs. These results were supported by another Chinese study that there was a lower rate of severe diseases and a lower rate of the inflammatory response in COVID-19 patients treated with ACEI and ARBs versus patients treated with other antihypertensive agents (27). However, some in vitro and animal studies have demonstrated that ACEI and ARBs increased the expression of ACE2, and those drugs could facilitate the infection of target organs and exacerbate COVID19 disease progression $(28,29)$. Moreover, the detailed relationship between ACEI and the renin-angiotensin system (RAS) in humans is not yet clearly understood (30). In recent systematic reviews and meta-analysis studies, data showed that hypertension is one of the major comorbidities in COVID-19 fatal cases (31) and COVID-19 patients with hypertension have a significantly increased mortality risk (32) and also a higher risk of ICU admission (33).

\section{Cardiovascular Disease}

A high prevalence of the cardiovascular disease has been observed in patients with COVID-19 (34) and clinical studies have also reported the association between COVID-19 and cardiovascular disease (35). Pre-existing cardiovascular disease was believed to be linked with poorer outcomes and increased risk of death in COVID-19 patients. Other studies have also observed higher troponin concentration in patients with more severe COVID-19 (36). Although the predominant clinical symptoms of COVID-19 is viral pneumonia (37-39), COVID19 can also cause cardiovascular complications such as myocardial injury, myocarditis, acute coronary syndrome 
(ACS), heart failure, arrhythmias, sudden cardiac arrest, coagulation abnormalities and thrombosis (40-43). A case study in South Korea reported that a COVID-19 patient was diagnosed as acute myocarditis and this patient presented very high levels of cardiac troponin I and N-terminal (NT) pro B-type natriuretic peptide (NTproBNP), the two most sensitive clinical biomarkers for myocardial injury (44), although no SRAS-Cov-2 genomes from myocardial biopsy samples were observed (45).

Recently, several cases of stress-induced cardiomyopathy with COVID-19 have been reported, while the past medical histories of these patients were unremarkable (45-47). The postulated underlying mechanism is that COVID-19 pneumonia decreased systemic oxygenation supply and while it inversely increased cardiac demand, immune dysregulation and electrolyte imbalance (48).

In summary, these findings suggest that cardiovascular disease is not only a common symptom of COVID-19 but also a risk factor for poor prognosis. Although we do not understand the mechanisms underlying COVID-19-related cardiovascular disease, this could be largely attributable to systemic inflammation based on the available clinical findings.

\section{Obesity}

Obesity is now being recognized as a risk factor for severe outcomes and the death of COVID-19. Evidence from around the world suggesting obese people are at greater risk of becoming seriously ill from COVID-19, means there must be an extra reason to take on obesity $(49,50)$. Importantly, a study of 4103 patients with COVID-19 disease in New York reported that the most important clinical features leading to hospital admission were aged (over 65 years) and obesity itself, more than hypertension, cardiovascular disease or diabetes (51). In this study, body mass index (BMI, $>40 \mathrm{~kg} / \mathrm{m}^{2}$ ) is one of the strongest hospitalization risks for COVID-19 positive patients. This finding was consistent with the results from the CORONADO study. It was found that in people with diabetes hospitalized for COVID-19, BMI $\left(>40 \mathrm{~kg} / \mathrm{m}^{2}\right)$ was independently associated with the severity of COVID-19 but not long-term glycemic control assessed by HbAlc (8). Multiple underlying mechanisms are accounted for this association. Firstly, the alteration of respiratory performance and impaired lung perfusion may be due to abdominal fat (52) and intravascular disseminated coagulation (53). Secondly, pre-existing comorbidities such as hypertension and diabetes are prothrombotic conditions $(54,55)$ that contribute to worse prognosis in COVID-19 patients. This was supported by a Germany autopsy study that found that deep venous thromboembolism was observed in 7 of 12 patients and pulmonary embolism was the direct cause of death for 4 patients (56). Finally, obesity is often linked with inadequate and excessive immunological responses and chronic inflammation which could rapidly mediate disease progression to multi-organ failure in severe COVID-19 patients (57).

Furthermore, another explanation is based on the findings that SARS-CoV-2 has a high affinity for human ACE2. And ACE2 is much highly expressed in adipose tissue compared to that in the lung, major SARS-CoV-2 target tissue and obese individuals have more adipose tissue, therefore an increased ACE2-expressing cell numbers and consequently a larger amount of ACE2 (58). ACE2 was believed to be the receptor for the entry of SARS-CoV-2 into host cells (59).

\section{Inflammation}

Higher levels of inflammatory markers in the blood (such as C-reactive protein and ferritin), an increased neutrophil-tolymphocyte ratio and increased serum levels of inflammatory cytokines and chemokines have been associated with COVID-19 disease severity and death $(51,60)$. The cytokine profiles in severe COVID-19 patients are similar to those in cytokine release syndromes, with increased production of cytokines such as interleukin (IL)-6, IL-7 and tumor necrosis factor (TNF) and also CXC-chemokine ligand 10 (CXCL10) (61). Studies have reported that inflammatory infiltration was observed in the lung, heart, kidney, spleen, and lymph nodes (62-64). Several reports have also observed higher concentrations of C-reactive protein, IL-6, IL-10, ferritin, leukocytes and lower lymphocyte percentage in severe COVID-19 patients compared to that of non-severe patients $(65,66)$. A low-grade systemic and chronic inflammation was often observed in diabetes. Thus, a dysregulated inflammatory innate and an adaptive impaired immune response consequently occur in diabetic patients. Therefore, a more severe disease in COVID-19 patients with diabetes may be the result of a cytokine storm, in which the patient's immune system fights against SARS-CoV-2 and inflicts compromised damage on its organs. Several studies have reported that COVID-19 patients with diabetes have higher lymphopenia incidence and increased proinflammatory biomarkers than those without diabetes $(67,68)$. Moreover, increased inflammation such as elevated IL- 6 and TNF levels were also observed in obese patients, thus favors COVID-19 disease progression, and worsens the lung and heart functions (69). Therefore, obesity is also an important predisposing factor for this phenomenon.

\section{Hyperglycemia-the Importance of Glycemic Control}

Diabetes is characterized by impaired glucose homeostasis resulting from insulin resistance or deficiency. As we know, diabetes is a well-established risk factor and predictor for elevated morbidity and mortality in various diseases such as cardiovascular diseases, cancer, and infection diseases (70-73).

In a cohort of 1561 patients with COVID-19 in two hospitals from Wuhan, those with diabetes are more likely to require an intensive care unit (ICU) admission or to die (16). In a centered, retrospective study, Yang et al. demonstrated that among cases with a poor outcome, in a group of 32 non-survivors of 52 ICU patients, 7 (22\%) had diabetes (74). Data from a British hospital including 10926 COVID-19 related death in a cohort of 17278392 adults showed that the risk of death is much higher in those with uncontrolled diabetes (20). Other studies also described that there was a worse outcome in COVID-19 patients is diabetes (75), therefore, result in more hospitalizations, more admission for ICU and more death (33). 
As we know, the virulence of some pathogens is increased during the hyperglycemic environment. It was reported that phagocytosis and chemotaxis are impaired and the production of $\mathrm{T}$ cells and neutrophils in response to infection is also reduced in diabetes (76). Generally, the immune response is damaged in diabetic COVID-19 patients with poor blood glucose control. Among the COVID-19 patients with diabetes, higher incidences of neutrophilia and lymphopenia are observed in those with higher levels of blood glucose concentration (67). Recently, several studies have shown that impaired pulmonary function significantly correlates with blood glucose levels $(77,78)$. Therefore, the vulnerability to respiratory infections is increased along with reduced pulmonary capacity. This might be another factor that diabetes is more commonly observed in severe COVID-19 patients. Moreover, in a total of 663 COVID19 patients' study, type 2 diabetes was found to be associated with no improvement in patients with COVID-19 and type 2 diabetes patients were prone to developing into severe and critical condition of COVID-19 and having a poorer therapeutic effect. Furthermore, having a severe and critical condition and decreased lymphocyte count were independent risk factors associated with poor therapeutic effects in COVID-19 patients with type 2 diabetes (79). Interestingly, in a populationbased cohort study with diagnosed type 1 and type 2 diabetes in England, Holman found that increased COVID-19-related mortality was associated not only with cardiovascular and renal complications of both types of diabetes but also independently with glycemic control and BMI (80).

A recent study reported that COVID-19 patients with diabetes and uncontrolled hyperglycemia (defined as two or more blood glucose $>180 \mathrm{mg} / \mathrm{dL}$ within any 24-hour period with an $\mathrm{HbA1C}<$ $6.5 \%$ or no $\mathrm{HbA1C}$ testing during hospitalization) were associated with longer hospitalization and higher mortality (81). Studies also found that higher blood glucose concentration at admission was associated with the poorer primary outcome. In a retrospective analysis of 85 COVID-19 patients, Iacobellis et al. reported that hyperglycemia on the first day of admission is the best predictor of radiographic imaging, regardless of pre-existing diabetes (82). Furthermore, hyperglycemia during treatment was a risk factor for death in patients with severe COVID-19 (83). In a retrospective multi-center study including COVID-19 patients hospitalized in Spain, it was found that hyperglycaemia ( $>180$ $\mathrm{mg} / \mathrm{dL}$ ) is a strong predictor of all-cause mortality in non-critically hospitalized COVID-19 patients regardless of diabetes history (84). Thus, glucose testing and glycemic control are important to all COVID-19 patients even without pre-existing diabetes, as most COVID-19 patients are prone to glucose metabolic disorders. This is because the ACE receptors where SARS-CoV-2 binds to enter target cells are also expressed in pancreatic $\beta$ cells (24). This could induce acute impairment of insulin secretion and $\beta$ cell destruction resulting in de novo diabetes development.

In summary, uncontrolled glycemic at admission and hospitalization exacerbate poor outcomes of COVID-19 patients. In COVID-19 patients with hyperglycemia, therapeutic strategies combined with glycemic control should be considered to reduce the risk of severe outcomes and mortality.

\section{THERAPEUTICS-TREATMENT SPECIFIC TO PATIENTS HAVING BOTH COVID-19 AND DIABETES}

Medical teams should ensure sufficient glycemic control in COVID-19 patients with diabetes. This requires full consideration of all potential complications the therapies may generate which will be used for those patients.

Insulin treatment is a general therapy for both types of diabetes. However, insulin therapy should be decided based on the severity of COVID-19 and those patients should be intensely monitored, although this treatment has been recommended in severe COVID-19 patients with diabetes (85). One study found that poorer clinical outcomes in patients treated with insulin compared with those under metformin treatment (7). Despite better outcomes reported in diabetic patients with COVID-19 on metformin, this drug should be discontinued if patients with respiratory distress, renal dysfunction, or heart failure due to acidosis (85). In the CORONADO study, Cariou et al. reported that the use of metformin was lower in patients who died and other therapies such as insulin treatment, renin-angiotensinaldosterone system (RAAS) blockers, $\beta$-blockers and loop diuretics were associated with death on day 7 . They believed this finding could be attributed to the underling comorbidities and diabetic complications in people who died because these patients were received more frequent treatment including insulin and other multiples drugs (8). A recent study reported significantly higher postprandial glycemic fluctuations and exposure to hyperglycemia were observed among patients with COVID-19 followed by continuous glucose monitoring (86). Thus, continuous blood glucose monitoring should also be included during the treatment process.

Sodium-glucose transporter 2 inhibitors should also be treated with caution due to their adverse effects such as ketoacidosis and impaired fat metabolism (87). Besides, Care should also be taken with the use of glucagon-like receptor-1 (GLP-1R) analogues since they may cause diarrhea, nausea, vomiting and headaches (88). In a recent multicenter, casecontrol, retrospective, and observational study, sitagliptin, an oral and highly selective dipeptidyl peptidase 4 (DPP4) inhibitor, was used as an add-on therapy to the standard of care in patients with type 2 diabetes and COVID-19. Sitagliptin treatment was found to be associated with reduced mortality, an improved clinical outcome and a greater number of hospital discharges in this study (89). These beneficial effects may be attributed to the shared disease pathophysiology pathways in coronavirus infections and type 2 diabetes. DPP4 and ACE2, two major coronavirus receptor proteins, are well-established transducers of metabolic signals and pathways regulating inflammation, cardiorenal physiology, and glucose homeostasis. Moreover, glucose-lowering drugs such as the DPP4 inhibitors, widely used in type 2 diabetes patients, are known to modify the biological activities of multiple immunomodulatory substrates (90).

As we know, it is a multistep process for virus infection. Researchers have proposed several targets to treat COVID-19. 
The beneficial effects of ACEI and ARBs for kidney and heart in diabetes have already been proven (91). However, as stated above, for COVID-19 patients with diabetes, the use of ACEI and ARBs for those patients should be carefully discussed based on the context of the individuals.

Glucocorticoids are known to cause hyperglycemia in patients with or without pre-existing diabetes. However, it has been used for the treatment of severely ill patients to suppress the very high levels of cytokines and c-reactive peptides which are often observed in those patients, although they can exacerbate insulin resistance, reduce insulin sensitivity and cause severe hyperglycemia. No studies have found that they could decrease mortality or slow viral clearance in clinical.

\section{CONCLUSIONS}

Patients with COVID-19 and diabetes are at greater risk for more severe infections, poorer prognosis and much higher mortality compared to those patients without diabetes. The grave prognosis and the risk factors for patients with diabetes are well linked with older age, sex, high blood pressure, cardiovascular disease, obesity, inflammation and hyperglycemia. All those factors contribute to the increased risk of getting severely ill in those individuals. It is a great

\section{REFERENCES}

1. World Health Organization. Coronavirus Disease (COVID-2019) Situation Reports (2021). Available at: https://www.who.int/emergencies/diseases/ novel-coronavirus-2019/situation-reports/.

2. Lu R, Zhao X, Li J, Niu P, Yang B, Wu H, et al. Genomic Characterisation and Epidemiology of 2019 Novel Coronavirus: Implications for Virus Origins and Receptor Binding. Lancet (2020) 395:565-74. doi: 10.1016/S0140-6736(20) 30251-8

3. Hellewell J, Abbott S, Gimma A, Bosse NI, Jarvis CI, Russell TW, et al. Feasibility of Controlling COVID-19 Outbreaks by Isolation of Cases and Contacts. Lancet Glob Health (2020) 8:e488-96. doi: 10.1016/S2214-109X(20)30074-7

4. World Health Organization. Middle East Respiratory Syndrome Coronavirus (MERS-Cov) (2020). Available at: https://www.who.int/health-topics/middleeast-respiratory-syndrome-coronavirus-mers\#tab=tab_1.

5. World Health Organization. Severe Acute Respiratory Syndrome (Sars) (2020). Available at: https://www.who.int/health-topics/severe-acute-respiratorysyndrome\#tab=tab_1.

6. Yang J, Zheng Y, Gou X, Pu K, Chen Z, Guo Q, et al. Prevalence of Comorbidities and its Effects in Patients Infected With SARS-CoV-2: A Systematic Review and Meta-Analysis. Int J Infect Dis IJID Off Publ Int Soc Infect Dis (2020) 94:91-5. doi: 10.1016/j.ijid.2020.03.017

7. Chen Y, Yang D, Cheng B, Chen J, Peng A, Yang C, et al. Clinical Characteristics and Outcomes of Patients With Diabetes and COVID-19 in Association With Glucose-Lowering Medication. Diabetes Care (2020) 43:1399-407. doi: 10.2337/dc20-0660

8. Cariou B, Hadjadj S, Wargny M, Pichelin M, Al-Salameh A, Allix I, et al. Phenotypic Characteristics and Prognosis of Inpatients With COVID-19 and Diabetes: The CORONADO Study. Diabetologia (2020) 63:1500-15. doi: 10.1007/s00125-020-05180-x

9. Wu Z, McGoogan JM. Characteristics of and Important Lessons From the Coronavirus Disease 2019 (Covid-19) Outbreak in China: Summary of a Report of 72314 Cases From the Chinese Center for Disease Control and Prevention. Jama (2020) 323:1239-42. doi: 10.1001/jama.2020.2648

10. Huang C, Wang Y, Li X, Ren L, Zhao J, Hu Y, et al. Clinical Features of Patients Infected With 2019 Novel Coronavirus in Wuhan, China. Lancet (2020) 395:497-506. doi: 10.1016/S0140-6736(20)30183-5 challenge for blood glucose management in COVID-19 patients because it requires more detailed strategies for medical team integration and fully considerations of all possible complications and death.

It is also clear that the relationship between diabetes and COVID-19 is tightly linked together and it requires more research to fully uncover the specific mechanisms of SARSCoV-2 such as how SARS-CoV-2 impairs the pancreatic islets, deteriorates insulin homeostasis and induce de novo diabetes development.

\section{AUTHOR CONTRIBUTIONS}

SJ and WH wrote different sections of the manuscript. WH revised, wrote, and prepared the manuscript. All authors contributed to the article and approved the submitted version.

\section{FUNDING}

This work was supported by the Department of Science and Technology of Liaoning province (2019-ZD-0774).

11. Booth CM, Matukas LM, Tomlinson GA, Rachlis AR, Rose DB, Dwosh HA, et al. Clinical Features and Short-Term Outcomes of 144 Patients With SARS in the Greater Toronto Area. Jama (2003) 289:2801-9. doi: 10.1001/ jama.289.21.JOC30885

12. Orioli L, Hermans MP, Thissen JP, Maiter D, Vandeleene B, Yombi JC. Covid19 in Diabetic Patients: Related Risks and Specifics of Management. Ann Endocrinol (Paris) (2020) 81:101-9. doi: 10.1016/j.ando.2020.05.001

13. Zheng Z, Peng F, Xu B, Zhao J, Liu H, Peng J, et al. Risk Factors of Critical \& Mortal COVID-19 Cases: A Systematic Literature Review and Meta-Analysis. J Infect (2020) 81:e16-25. doi: 10.1016/j.jinf.2020.04.021

14. Voinsky I, Baristaite G, Gurwitz D. Effects of Age and Sex on Recovery From COVID-19: Analysis of 5769 Israeli Patients. J Infect (2020) 81:e102-3. doi: 10.1016/j.jinf.2020.05.026

15. Cdc Weekly C. The Epidemiological Characteristics of an Outbreak of 2019 Novel Coronavirus Diseases (Covid-19) - China, 2020. China CDC Weekly (2020) 2:113-22. doi: 10.46234/ccdcw2020.032

16. Shi Q, Zhang X, Jiang F, Zhang X, Hu N, Bimu C, et al. Clinical Characteristics and Risk Factors for Mortality of COVID-19 Patients With Diabetes in Wuhan, China: A Two-Center, Retrospective Study. Diabetes Care (2020) 43:1382-91. doi: 10.2337/dc20-0598

17. World Health Organization. Gender and COVID-19 (2020). Available at: https://www.who.int/publications/i/item/gender-and-covid-19.

18. Klein SL, Dhakal S, Ursin RL, Deshpande S, Sandberg K, Mauvais-Jarvis F. Biological Sex Impacts COVID-19 Outcomes. PloS Pathog (2020) 16: e1008570. doi: 10.1371/journal.ppat.1008570

19. Zeng F, Dai C, Cai P, Wang J, Xu L, Li J, et al. A Comparison Study of SARSCoV-2 Igg Antibody Between Male and Female COVID-19 Patients: A Possible Reason Underlying Different Outcome Between Sex. J Med Virol (2020) 92:2050-4. doi: 10.1101/2020.03.26.20040709

20. Williamson EJ, Walker AJ, Bhaskaran K, Bacon S, Bates C, Morton CE, et al. Factors Associated With COVID-19-related Death Using Opensafely. Nature (2020) 584:430-6. doi: 10.1038/s41586-020-2521-4

21. European Centre for Disease prevention and Control. Coronavirus Disease 2019 (COVID-19) in the EU/EEA and the UK - Eleventh Update: Resurgence of Cases (2020). Available at: https://www.ecdc.europa.eu/en/publications-data/ rapid-risk-assessment-coronavirus-disease-2019-covid-19-eueea-and-ukeleventh. 
22. Guan WJ, Liang WH, Zhao Y, Liang HR, Chen ZS, Li YM, et al. Comorbidity and its Impact on 1590 Patients With COVID-19 in China: A Nationwide Analysis. Eur Respir J (2020) 55:2000547. doi: 10.1183/13993003.01227-2020

23. Cheng Y, Luo R, Wang K, Zhang M, Wang Z, Dong L, et al. Kidney Disease is Associated With in-Hospital Death of Patients With COVID-19. Kidney Int (2020) 97:829-38. doi: 10.1016/j.kint.2020.03.005

24. Hamming I, Timens W, Bulthuis ML, Lely AT, Navis G, van Goor H. Tissue Distribution of ACE2 Protein, the Functional Receptor for SARS Coronavirus. A First Step in Understanding SARS Pathogenesis. J Pathol (2004) 203:631-7. doi: 10.1002/path.1570

25. Gheblawi M, Wang K, Viveiros A, Nguyen Q, Zhong JC, Turner AJ, et al. Angiotensin-Converting Enzyme 2: SARS-CoV-2 Receptor and Regulator of the Renin-Angiotensin System: Celebrating the 20th Anniversary of the Discovery of ACE2. Circ Res (2020) 126:1456-74. doi: 10.1161/ CIRCRESAHA.120.317015

26. Xu X, Chen P, Wang J, Feng J, Zhou H, Li X, et al. Evolution of the Novel Coronavirus From the Ongoing Wuhan Outbreak and Modeling of its Spike Protein for Risk of Human Transmission. Sci China Life Sci (2020) 63:457-60. doi: 10.1007/s11427-020-1637-5

27. Meng J, Xiao G, Zhang J, He X, Ou M, Bi J, et al. Renin-Angiotensin System Inhibitors Improve the Clinical Outcomes of COVID-19 Patients With Hypertension. Emerg Microbes Infect (2020) 9:757-60. doi: 10.1080/ 22221751.2020.1746200

28. Arendse LB, Danser AHJ, Poglitsch M, Touyz RM, Burnett JC Jr, LlorensCortes C, et al. Novel Therapeutic Approaches Targeting the ReninAngiotensin System and Associated Peptides in Hypertension and Heart Failure. Pharmacol Rev (2019) 71:539-70. doi: 10.1124/pr.118.017129

29. Igase M, Strawn WB, Gallagher PE, Geary RL, Ferrario CM. Angiotensin II AT1 Receptors Regulate ACE2 and Angiotensin-(1-7) Expression in the Aorta of Spontaneously Hypertensive Rats. American Journal of Physiology. Heart Circulatory Physiol (2005) 289:H1013-1019. doi: 10.1152/ajpheart.00068.2005

30. Takimoto-Ohnishi E, Murakami K. Renin-Angiotensin System Research: From Molecules to the Whole Body. J Physiol Sci (2019) 69:581-7. doi: 10.1007/s12576-019-00679-4

31. Chen Y, Gong X, Wang L, Guo J. Effects of Hypertension, Diabetes and Coronary Heart Disease on COVID-19 Diseases Severity: A Systematic Review and Meta-Analysis. medRxiv (2020) 2020:2003.2025.20043133. doi: 10.1101/2020.03.25.20043133

32. Zuin M, Rigatelli G, Zuliani G, Rigatelli A, Mazza A, Roncon L. Arterial Hypertension and Risk of Death in Patients With COVID-19 Infection: Systematic Review and Meta-Analysis. J Infect (2020) 81:e84-6. doi: 10.1016/j.jinf.2020.03.059

33. Roncon L, Zuin M, Rigatelli G, Zuliani G. Diabetic Patients With COVID-19 Infection are At Higher Risk of ICU Admission and Poor Short-Term Outcome. J Clin Virol Off Publ Pan Am Soc Clin Virol (2020) 127:104354. doi: 10.1016/j.jcv.2020.104354

34. Li B, Yang J, Zhao F, Zhi L, Wang X, Liu L, et al. Prevalence and Impact of Cardiovascular Metabolic Diseases on COVID-19 in China. Clin Res Cardiol (2020) 109:531-8. doi: 10.1007/s00392-020-01626-9

35. Nishiga M, Wang DW, Han Y, Lewis DB, Wu JC. Covid-19 and Cardiovascular Disease: From Basic Mechanisms to Clinical Perspectives. Nat Rev Cardiol (2020) 17:543-58. doi: 10.1038/s41569-020-0413-9

36. Li JW, Han TW, Woodward M, Anderson CS, Zhou H, Chen YD, et al. The Impact of 2019 Novel Coronavirus on Heart Injury: A Systematic Review and Meta-Analysis. Prog Cardiovasc Dis (2020) 63:518-24. doi: 10.1016/ j.pcad.2020.04.008

37. Wu F, Zhao S, Yu B, Chen YM, Wang W, Song ZG, et al. A New Coronavirus Associated With Human Respiratory Disease in China. Nature (2020) 579:265-9. doi: 10.1038/s41586-020-2008-3

38. Bhatraju PK, Ghassemieh BJ, Nichols M, Kim R, Jerome KR, Nalla AK, et al. Covid-19 in Critically Ill Patients in the Seattle Region - Case Series. New Engl $J$ Med (2020) 382:2012-22. doi: 10.1056/NEJMoa2004500

39. Onder G, Rezza G, Brusaferro S. Case-Fatality Rate and Characteristics of Patients Dying in Relation to COVID-19 in Italy. Jama (2020) 323:1775-6. doi: 10.1001/jama.2020.4683

40. Madjid M, Safavi-Naeini P, Solomon SD, Vardeny O. Potential Effects of Coronaviruses on the Cardiovascular System: A Review. JAMA Cardiol (2020) 5:831-40. doi: 10.1001/jamacardio.2020.1286
41. Clerkin KJ, Fried JA, Raikhelkar J, Sayer G, Griffin JM, Masoumi A, et al. Covid-19 and Cardiovascular Disease. Circulation (2020) 141:1648-55. doi: 10.1161/CIRCULATIONAHA.120.046941

42. Driggin E, Madhavan MV, Bikdeli B, Chuich T, Laracy J, Biondi-Zoccai G, et al. Cardiovascular Considerations for Patients, Health Care Workers, and Health Systems During the COVID-19 Pandemic. J Am Coll Cardiol (2020) 75:2352-71. doi: 10.1016/j.jacc.2020.03.031

43. Zheng YY, Ma YT, Zhang JY, Xie X. Covid-19 and the Cardiovascular System. Nat Rev Cardiol (2020) 17:259-60. doi: 10.1038/s41569-020-0360-5

44. Kim IC, Kim JY, Kim HA, Han S. Covid-19-related Myocarditis in a 21-YearOld Female Patient. Eur Heart J (2020) 41:1859. doi: 10.1093/eurheartj/ ehaa288

45. Sala S, Peretto G, Gramegna M, Palmisano A, Villatore A, Vignale D, et al. Acute Myocarditis Presenting as a Reverse Tako-Tsubo Syndrome in a Patient With SARS-CoV-2 Respiratory Infection. Eur Heart J (2020) 41:1861-2. doi: 10.1093/eurheartj/ehaa286

46. Tsao CW, Strom JB, Chang JD, Manning WJ. Covid-19-Associated Stress (Takotsubo) Cardiomyopathy. Circ Cardiovasc Imaging (2020) 13:e011222. doi: 10.1161/CIRCIMAGING.120.011222

47. Minhas AS, Scheel P, Garibaldi B, Liu G, Horton M, Jennings M, et al. Takotsubo Syndrome in the Setting of COVID-19. JACC Case Rep (2020) 2:1321-5. doi: 10.1016/j.jaccas.2020.04.023

48. Babapoor-Farrokhran S, Gill D, Walker J, Rasekhi RT, Bozorgnia B, Amanullah A. Myocardial Injury and COVID-19: Possible Mechanisms. Life Sci (2020) 253:117723. doi: 10.1016/j.lfs.2020.117723

49. Scheen AJ. Obesity and Risk of Severe COVID-19. Rev medicale suisse (2020) 16:1115-9.

50. Kassir R. Risk of COVID-19 for Patients With Obesity. Obes Rev an Off J Int Assoc Study Obes (2020) 21:e13034. doi: 10.1111/obr.13034

51. Petrilli CM, Jones SA, Yang J, Rajagopalan H, O’Donnell LF, Chernyak Y, et al. Factors associated with hospital admission and critical illness among 5279 people with coronavirus disease 2019 in New York City: prospective cohort study. BMJ (2020) 369:m1966. doi: 10.1136/bmj.m1966

52. Sattar N, McInnes IB, McMurray JJV. Obesity Is a Risk Factor for Severe Covid-19 Infection: Multiple Potential Mechanisms. Circulation (2020) 142:4-6. doi: 10.1161/CIRCULATIONAHA.120.047659

53. Connors JM, Levy JH. Covid-19 and its Implications for Thrombosis and Anticoagulation. Blood (2020) 135:2033-40. doi: 10.1182/blood.2020006000

54. Nadar S, Lip GY. The Prothrombotic State in Hypertension and the Effects of Antihypertensive Treatment. Curr Pharm Design (2003) 9:1715-32. doi: $10.2174 / 1381612033454559$

55. Ghosh K. Chapter 16. In: CC Kartha, S Ramachandran, RM Pillai, editors. Mechanisms of Vascular Defects in Diabetes Mellitus. Cham, Switzerland: Springer International Publishing (2017) 361-76. doi: 10.1007/978-3-31960324-7_16

56. Wichmann D, Sperhake JP, Lutgehetmann M, Steurer S, Edler C, Heinemann A, et al. Autopsy Findings and Venous Thromboembolism in Patients With Covid-19: A Prospective Cohort Study. Ann Internal Med (2020) 173:268-77. doi: 10.7326/L20-1206

57. Yang L, Liu S, Liu J, Zhang Z, Wan X, Huang B, et al. Covid-19: Immunopathogenesis and Immunotherapeutics. Signal Transduct Target Ther (2020) 5:128. doi: 10.1038/s41392-020-00243-2

58. Jia X, Yin C, Lu S, Chen Y, Liu Q, Bai J, et al. Two Things About COVID-19 Might Need Attention. Preprints (2020). doi: 10.20944/preprints202002. 0315.v1

59. Zhou P, Yang XL, Wang XG, Hu B, Zhang L, Zhang W, et al. A Pneumonia Outbreak Associated With a New Coronavirus of Probable Bat Origin. Nature (2020) 579:270-3. doi: 10.1038/s41586-020-2012-7

60. Zhou F, Yu T, Du R, Fan G, Liu Y, Liu Z, et al. Clinical Course and Risk Factors for Mortality of Adult Inpatients With COVID-19 in Wuhan, China: A Retrospective Cohort Study. Lancet (2020) 395:1054-62. doi: 10.1016/ S0140-6736(20)30566-3

61. Merad M, Martin JC. Pathological Inflammation in Patients With COVID-19: A Key Role for Monocytes and Macrophages. Nat Rev Immunol (2020) 20:355-62. doi: 10.1038/s41577-020-0331-4

62. Xu Z, Shi L, Wang Y, Zhang J, Huang L, Zhang C, et al. Pathological Findings of COVID-19 Associated With Acute Respiratory Distress Syndrome. Lancet Respir Med (2020) 8:420-2. doi: 10.1016/S2213-2600(20)30076-X 
63. Chen Y, Feng Z, Diao B, Wang R, Wang G, Wang C, et al. The Novel Severe Acute Respiratory Syndrome Coronavirus 2 (SARS-Cov-2) Directly Decimates Human Spleens and Lymph Nodes. medRxiv (2020). 2020.2003.2027.20045427. doi: 10.1101/2020.03.27.20045427

64. Diao B, Wang C, Wang R, Feng Z, Tan Y, Wang H, et al. Human Kidney is a Target for Novel Severe Acute Respiratory Syndrome Coronavirus 2 (SarsCoV-2) Infection. medRxiv (2020). 2020.2003.2004.20031120. doi: 10.1101/ 2020.03.04.20031120

65. Henry BM, de Oliveira MHS, Benoit S, Plebani M, Lippi G. Hematologic, Biochemical and Immune Biomarker Abnormalities Associated With Severe Illness and Mortality in Coronavirus Disease 2019 (COVID-19): A MetaAnalysis. Clin Chem Lab Med (2020) 58:1021-8. doi: 10.1515/cclm-2020-0369

66. Zhang JJ, Dong X, Cao YY, Yuan YD, Yang YB, Yan YQ, et al. Clinical Characteristics of 140 Patients Infected With SARS-CoV-2 in Wuhan, China. Allergy (2020) 75:1730-41. doi: 10.1111/all.14238

67. Zhu L, She ZG, Cheng X, Qin JJ, Zhang XJ, Cai J, et al. Association of Blood Glucose Control and Outcomes in Patients With COVID-19 and Pre-existing Type 2 Diabetes. Cell Metab (2020) 31:1068-77.e1063. doi: 10.1016/j.cmet. 2020.04.021

68. Guo W, Li M, Dong Y, Zhou H, Zhang Z, Tian C, et al. Diabetes is a Risk Factor for the Progression and Prognosis of COVID-19. Diabetes/Metab Res $\operatorname{Rev}(2020)$ 36:e3319. doi: 10.1002/dmrr.3319

69. Bhattacharya I, Ghayor C, Pérez Dominguez A, Weber FE. From Influenza Virus to Novel Corona Virus (SARS-Cov-2)-the Contribution of Obesity. Front Endocrinol (2020) 11:556962. doi: 10.3389/fendo.2020.556962

70. Wang S, Ma P, Zhang S, Song S, Wang Z, Ma Y, et al. Fasting Blood Glucose At Admission is an Independent Predictor for 28-Day Mortality in Patients With COVID-19 Without Previous Diagnosis of Diabetes: A Multi-Centre Retrospective Study. Diabetologia (2020) 63:2102-11. doi: 10.1007/s00125020-05209-1

71. Gregg EW, Cheng YJ, Srinivasan M, Lin J, Geiss LS, Albright AL, et al. Trends in Cause-Specific Mortality Among Adults With and Without Diagnosed Diabetes in the USA: An Epidemiological Analysis of Linked National Survey and Vital Statistics Data. Lancet (2018) 391:2430-40. doi: 10.1016/S0140-6736 (18)30314-3

72. Pearson-Stuttard J, Blundell S, Harris T, Cook DG, Critchley J. Diabetes and Infection: Assessing the Association With Glycaemic Control in PopulationBased Studies. Lancet Diabetes Endocrinol (2016) 4:148-58. doi: 10.1016/ S2213-8587(15)00379-4

73. Rao Kondapally Seshasai S, Kaptoge S, Thompson A, Di Angelantonio E, Gao P, Sarwar N, et al. Diabetes Mellitus, Fasting Glucose, and Risk of CauseSpecific Death. New Engl J Med (2011) 364:829-41. doi: 10.1056/ NEJMoa1008862

74. Yang X, Yu Y, Xu J, Shu H, Xia J, Liu H, et al. Clinical Course and Outcomes of Critically Ill Patients With SARS-CoV-2 Pneumonia in Wuhan, China: A Single-Centered, Retrospective, Observational Study. Lancet Respir Med (2020) 8:475-81. doi: 10.1016/S2213-2600(20)30079-5

75. Fadini GP, Morieri ML, Longato E, Avogaro A. Prevalence and Impact of Diabetes Among People Infected With SARS-Cov-2. J Endocrinol Invest (2020) 43:867-9. doi: 10.1007/s40618-020-01236-2

76. Peleg AY, Weerarathna T, McCarthy JS, Davis TM. Common Infections in Diabetes: Pathogenesis, Management and Relationship to Glycaemic Control. Diabetes/Metab Res Rev (2007) 23:3-13. doi: 10.1002/dmrr.682

77. Yeh HC, Punjabi NM, Wang NY, Pankow JS, Duncan BB, Cox CE, et al. Cross-Sectional and Prospective Study of Lung Function in Adults With Type 2 Diabetes: The Atherosclerosis Risk in Communities (ARIC) Study. Diabetes Care (2008) 31:741-6. doi: 10.2337/dc07-1464

78. Shah SH, Sonawane P, Nahar P, Vaidya S, Salvi S. Pulmonary Function Tests in Type 2 Diabetes Mellitus and Their Association With Glycemic Control and Duration of the Disease. Lung India Off Organ Indian Chest Soc (2013) 30:108-12. doi: 10.4103/0970-2113.110417
79. Wang X, Liu Z, Li J, Zhang J, Tian S, Lu S, et al. Impacts of Type 2 Diabetes on Disease Severity, Therapeutic Effect, and Mortality of Patients With Covid-19. J Clin Endocrinol Metab (2020) 105:dgaa535. doi: 10.1210/ clinem/dgaa535

80. Holman N, Knighton P, Kar P, O'Keefe J, Curley M, Weaver A, et al. Risk Factors for COVID-19-related Mortality in People With Type 1 and Type 2 Diabetes in England: A Population-Based Cohort Study. Lancet Diabetes Endocrinol (2020) 8:823-33. doi: 10.1016/S2213-8587(20)30271-0

81. Bode B, Garrett V, Messler J, McFarland R, Crowe J, Booth R, et al. Glycemic Characteristics and Clinical Outcomes of COVID-19 Patients Hospitalized in the United States. J Diabetes Sci Technol (2020) 14:813-21. doi: 10.1177/ 1932296820924469

82. Iacobellis G, Penaherrera CA, Bermudez LE, Bernal Mizrachi E. Admission Hyperglycemia and Radiological Findings of SARS-CoV2 in Patients With and Without Diabetes. Diabetes Res Clin Pract (2020) 164:108185. doi: 10.1016/j.diabres.2020.108185

83. Li X, Xu S, Yu M, Wang K, Tao Y, Zhou Y, et al. Risk Factors for Severity and Mortality in Adult COVID-19 Inpatients in Wuhan. J Allergy Clin Immunol (2020) 146:110-8. doi: 10.1016/j.jaci.2020.04.006

84. Carrasco-Sánchez FJ, López-Carmona MD, Martínez-Marcos FJ, PérezBelmonte LM, Hidalgo-Jiménez A, Buonaiuto V, et al. Admission Hyperglycaemia as a Predictor of Mortality in Patients Hospitalized With COVID-19 Regardless of Diabetes Status: Data From the Spanish SemiCOVID-19 Registry. Ann Med (2021) 53:103-16. doi: 10.1080/ 07853890.2020 .1836566

85. Bornstein SR, Rubino F, Khunti K, Mingrone G, Hopkins D, Birkenfeld AL, et al. Practical Recommendations for the Management of Diabetes in Patients With COVID-19. Lancet Diabetes Endocrinol (2020) 8:546-50. doi: 10.1016/ S2213-8587(20)30152-2

86. Shen Y, Zhang L, Fan X, Zhou J. Glycemic Fluctuations Caused by COVID-19: Results From Continuous Glucose Monitoring. Obes Med (2021) 22:100328. doi: 10.1016/j.obmed.2021.100328

87. Hsia DS, Grove O, Cefalu WT. An Update on Sodium-Glucose Co-Transporter-2 Inhibitors for the Treatment of Diabetes Mellitus. Curr Opin Endocrinol Diabetes Obes (2017) 24:73-9. doi: 10.1097/MED.0000000000000311

88. Filippatos TD, Panagiotopoulou TV, Elisaf MS. Adverse Effects of GLP-1 Receptor Agonists. Rev Diabetic Stud RDS (2014) 11:202-30. doi: 10.1900/ RDS.2014.11.202

89. Solerte SB, D'Addio F, Trevisan R, Lovati E, Rossi A, Pastore I, et al. Sitagliptin Treatment At the Time of Hospitalization was Associated With Reduced Mortality in Patients With Type 2 Diabetes and COVID-19: A Multicenter, Case-Control, Retrospective, Observational Study. Diabetes Care (2020) 43:2999-3006. doi: 10.2337/dc20-1521

90. Drucker DJ. Coronavirus Infections and Type 2 Diabetes-Shared Pathways With Therapeutic Implications. Endocrine Rev (2020) 41:bnaa011. doi: 10.1210/endrev/bnaa011

91. Gillespie EL, White CM, Kardas M, Lindberg M, Coleman CI. The Impact of ACE Inhibitors or Angiotensin II Type 1 Receptor Blockers on the Development of New-Onset Type 2 Diabetes. Diabetes Care (2005) 28:2261-6. doi: $10.2337 /$ diacare.28.9.2261

Conflict of Interest: The authors declare that the research was conducted in the absence of any commercial or financial relationships that could be construed as a potential conflict of interest.

Copyright (c) 2021 Jin and Hu. This is an open-access article distributed under the terms of the Creative Commons Attribution License (CC BY). The use, distribution or reproduction in other forums is permitted, provided the original author(s) and the copyright owner(s) are credited and that the original publication in this journal is cited, in accordance with accepted academic practice. No use, distribution or reproduction is permitted which does not comply with these terms. 